\title{
Dihydrogergotamine, but not naloxone, counteracts lithium as an inhibitor of glucose-induced insulin release in isolated rat islets in vitro
}

\author{
T. Fontela, O. Garcia Hermida and J. Gómez-Acebo \\ Instituto Gregorio Marañon, C. I. B., C. S. I.C., Madrid, Spain
}

\begin{abstract}
Summary. Lithium exerts an inhibitory effect on glucose-induced insulin release. Lithium $(5 \mathrm{mmol} / 1)$ added $30 \mathrm{~min}$ prior to glucose stimulation or together with glucose $(16.7 \mathrm{mmol} / 1)$ failed to affect first phase, but reduced second phase glucoseinduced insulin release by $35 \%$. Similar results were obtained when islets isolated from rats following long-term oral lithium treatment were perifused with glucose $(16.7 \mathrm{mmol} / \mathrm{l})$. The inhibitory effect of lithium was counteracted by pretreatment of
\end{abstract}

the rats with the alpha-adrenergic blocking agent dihydroergotamine, whereas the opiate antagonist naloxone had no apparent effect on lithium-induced inhibition of glucose-stimulated insulin release.

Key words: Lithium, isolated islets, glucose-induced insulin release, dihydroergotamine, naloxone.
Lithium, an alkali metal used for treatment and prophylaxis of affective disorders, has been shown to cause impaired glucose tolerance [1-3]. This has been attributed to an inhibition of insulin release observed both in vivo $[2,3]$ and in vitro [4]. The mechanism by which lithium inhibits insulin release, however, has not been elucidated so far. In recent in vivo work [3], it has been demonstrated that naloxone, an opiate antagonist, and dihydroergotamine (DHE), an alpha-adrenergic blocking agent, abolished the hyperglycaemic effect as well as the inhibitory effect of lithium on glucose-stimulated insulin release. The present study was carried out in vitro to investigate the effects of lithium on glucose-stimulated insulin release from isolated rat islets. The aim of the study was to test whether those effects were due to a primary effect of the ion on B cells or to secondary effects produced by lithium-induced alterations in opioids and catecholamines systems as described in vivo.

\section{Materials and methods}

\section{Animals and drug administration}

Male rats of the Wistar-derived strain weighing 300-350 g were used as source of pancreatic islets for all experiments. The animals were fed with commercial chow and housed under a 12-h light/dark cycle. When required, rats were pretreated with intravenous injections of either saline or dihydroergotamine (DHE) $(0.3 \mathrm{mg} / \mathrm{kg}$ ) (Dihydergot,
Sandoz Pharmaceutical Co., Basel, Switzerland) $20 \mathrm{~min}$ prior to islet isolation, and/or with intraperitoneal injections of either saline or naloxone (17-allyl-4,5- epoxy-3,14 dihydroxymorphinan-6-one) $(0.5 \mathrm{mg} / \mathrm{kg}$ ) (Endo Laboratories, New York, NY, USA) in a volume of $10 \mu \mathrm{l} / \mathrm{g}$ body weight $20 \mathrm{~min}$ prior to islet isolation. All drugs were dissolved in $0.9 \% \mathrm{NaCl}$. Both drugs were also tested in vitro. DHE and/ or naloxone were added to the perifusion medium, yielding concentrations of $4 \mu \mathrm{g} / \mathrm{ml}$ and $2 \mu \mathrm{g} / \mathrm{ml}$, respectively.

\section{Isolation and perifusion of islets for measurement of insulin release}

Pancreatic islets were isolated from control rats and from DHE and/ or naloxone-pretreated rats by the collagenase digestion technique [5]. The islets were perifused using 50 islets per chamber (chamber volume $0.95 \mathrm{ml}$, Millipore; 5 micromillipore filter) as described in detail previously [6]. Two or four chambers were used in parallel depending of the design of the experiment. In the four chamber experiments, two chambers contained control islets and the other two contained islets from the drug-pretreated rats. Two perifusion media were employed: a standard perifusion medium for the first 30 -min periods and control chambers, with a normal ionic composition (i.e. $\mathrm{Na}+139, \mathrm{~K}+5$, $\mathrm{Ca}++2, \mathrm{Mg}++2, \mathrm{Cl}-124$, and $\left.\mathrm{CO}_{3} \mathrm{H}-24 \mathrm{mEq} / \mathrm{l}: \mathrm{pH} 7.4\right)$; and a perifusion medium for the last $90-\mathrm{min}$ period in the experimental chambers, in which portions of $0.9 \% \mathrm{NaCl}$ were replaced by equal volumes of $0.65 \%$ lithium chloride $(\mathrm{LiCl}$ ) (iso-osmotic with $0.9 \%$ $\mathrm{NaCl}$ ) to give the desired concentration of lithium in the medium. In one set of six experiments, the islets in the experimental chamber were perifused with the lithium medium 30 min prior to glucose stimulation, whereas the control chamber was perifused with a standard perifusion medium. Both media were supplemented with $5 \mathrm{mg} / \mathrm{ml}$ bovine albumin, fraction V (Sigma Chemical Co, St. Louis, Mo USA) and glucose (E. Merck AG, Darmstadt, FRG) as required, $3.2 \mathrm{mmol} / \mathrm{l}$ in the first $30 \mathrm{~min}$ of perifusion and $16.7 \mathrm{mmol} / 1$ in the second $90 \mathrm{~min}$. 


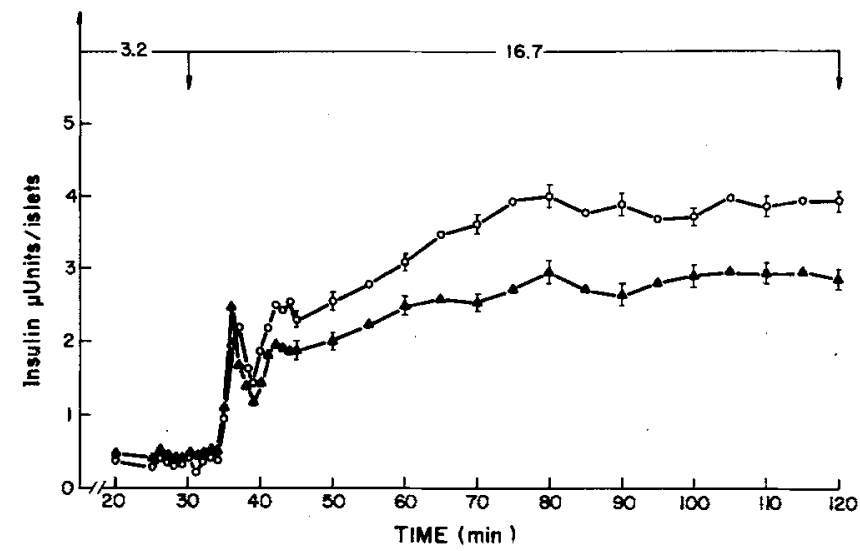

Fig. 1. Effect of lithium on glucose-stimulated insulin release. Islets were perifused for $30 \mathrm{~min}$ with a normal ionic composition medium containing $3.2 \mathrm{mmol} / 1$ glucose. They were then exposed to $16.7 \mathrm{mmol} / 1$ glucose, the control chamber in normal ionic composition medium (O) and experimental chamber in a lithium $(5 \mathrm{mmol} / 1)$ medium ( $\Delta$ ), for another $90 \mathrm{~min}$. Both conditions were always carried out in parallel chambers. Values in the curves are means \pm SEM of results from 6 to 8 separate experiments

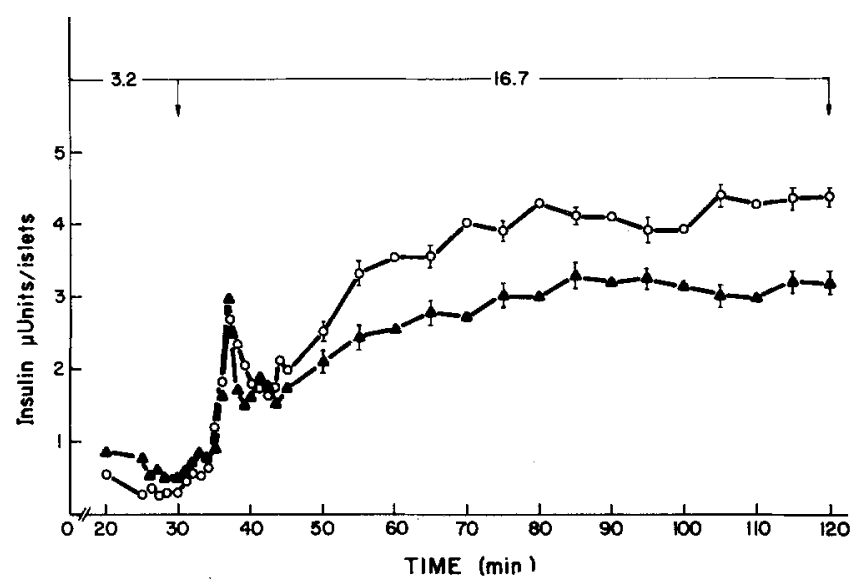

Fig. 2. Effect of preperifusion with the lithium medium on the biphasic pattern of glucose-induced insulin release. Islets in the control chamber were perifused with normal ionic composition medium prior and after glucose stimulation $(O)$. Islets in the experimental chamber were perifused for $30 \mathrm{~min}$ prior to glucose stimulation with the lithium medium containing glucose, $3.2 \mathrm{mmol} / 1$. They were then exposed to $16.7 \mathrm{mmol} / 1$ glucose in the same lithium medium $(\Delta)$ for another $90 \mathrm{~min}$. Both conditions were always carried out in parallel chambers. Values in the curves are means \pm SEM of results from 6 to 8 separate experiments

The media were gassed with $95 \% \mathrm{O}_{2}$ and $5 \% \mathrm{CO}_{2}$ delivered at a flow rate of $0.9-1 \mathrm{ml} / \mathrm{min}$, and were collected in graduated tubes at $1-$ or 5 -min intervals. The volumes collected were recorded, and aliquots were removed for insulin assay. The insulin content of the perifusate was measured by radio-immunoassay (Amersham, Buckinghamshire, UK) using rat insulin standard. The rate of insulin secretion was expressed as microunits of insulin $\times$ islet $^{-1} \times \min ^{-1}$. At least six experiments were performed for each experimental situation.

\section{Chronic lithium treatment}

Male Wistar rats weighing $110 \pm 10 \mathrm{~g}$ at the start of the treatment were divided into two groups of 12 rats each. The rats were housed in individual cages in a thermostatically controlled room $\left(20 \pm 2^{\circ} \mathrm{C}\right)$ on a 12-h light/dark cycle with free access to rat chow. One group received only $15 \mathrm{mmol} / \mathrm{L} \mathrm{LiCl}$ to drink (daily intake approximately $1-2 \mathrm{mmol} /$ $\mathrm{kg}$ ), while the other group received only distilled water to drink (control group) for 3 months. The rats were weighed once a week. Pancreatic islets were isolated from control and from lithium-treated rats. Two chambers were used in parallel, with one of them containing control islets and the other containing islets from the lithium-treated rats. Both chambers were perifused with a standard perifusion medium and stimulated with glucose as described above.

\section{Statistical analysis}

The results are expressed as the mean \pm SEM of the observed values. Significances of difference were estimated by Student's t-test for unpaired data; $p$ values of 0.05 or less were considered significant.

\section{Results}

\section{Acute lithium experiments}

As shown in Figure 1 (control chamber), $16.7 \mathrm{mmol} / 1$ glucose elicited a biphasic release of insulin. Insulin release started to rise 5-6 min after the increase of the glucose concentration from $3.2 \mathrm{mmol} / 1$ to $16.7 \mathrm{mmol} / 1$. A first peak at $7-8 \mathrm{~min}$ was followed by a nadir at $10-12 \mathrm{~min}$ and a progressively increasing second phase. Islets in the experimental chamber were perifused during the first $30 \mathrm{~min}$ with normal ionic composition medium. Following this period lithium was added at the time of glucose stimulation. The effect of lithium on the biphasic pattern of glucose-induced insulin secretion is illustrated in Figure 1. Lithium added at the time of glucose stimulation produced no significant decrease in the total insulin released in the first phase (first $8 \mathrm{~min}$ ), whereas the second phase of release was clearly inhibited. Integrated insulin release during the first phase was $16 \pm 3 \mu \mathrm{U} /$ islet for $16.7 \mathrm{mmol} / 1$ glucose alone, and not significantly different from $16.7 \mathrm{mmol} / 1$ glucose + lithium $(13 \pm 2, p>0.10)$; second phase release was $267 \pm 21$ and $165 \pm 14 \mu U$ /islet, respectively $(p<$ 0.05 ), which corresponds to an inhibition of $35 \%$.

The effect of preperifusion of islets with the lithium medium on the biphasic pattern of glucose-induced insulin secretion is shown in Figure 2. Pretreatment with lithium produced no significant decrease in the total insulin released during the first phase $(19 \pm 6 \mu \mathrm{U} /$ islet; control islets released $16 \pm 4 \mu \mathrm{U} /$ islet, $p>0.10$ ), whereas the second phase of release was clearly inhibited (total insulin released in the second phase by control islets was $275 \pm 23 \mu \mathrm{U} /$ islet, significantly different from insulin released by the lithium-treated islets $(183 \pm 19, p<$ 0.05).

\section{Effect of DHE and naloxone on lithium-induced inhibition of glucose-stimulated insulin release}

When tested in vitro, DHE and/or naloxone did not counteract the reduction in glucose-stimulated insulin release (results not shown). 


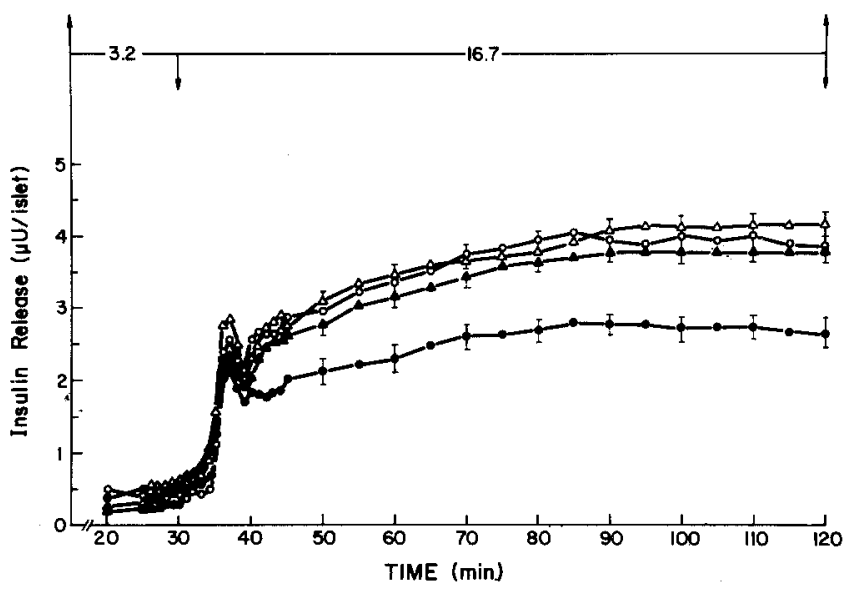

Fig.3. Effect of pretreatment with vehicle or dihydroergotamine $(0.3 \mathrm{mg} / \mathrm{kg})$ on the inhibitory effect of lithium on glucose-induced insulin release. Following isolation, islets were perifused for $30 \mathrm{~min}$ with $3.2 \mathrm{mmol} / 1$ glucose. They were then exposed to $16.7 \mathrm{mmol} / 1$ glucose in a normal ionic composition medium; vehicle-pretreated islets $(O)$ and dihydroergotamine (DHE)-pretreated islets $(\Delta)$ or in a lithium $(5 \mathrm{mmol} / 1)$ medium; vehicle-pretreated islets $(\Delta)$ and DHE-pretreated islets $(\boldsymbol{\Lambda})$. All conditions were always carried out in parallel chambers. Values in the curves are means \pm SEM of results from 6 to $8 \mathrm{sep}-$ arate experiments

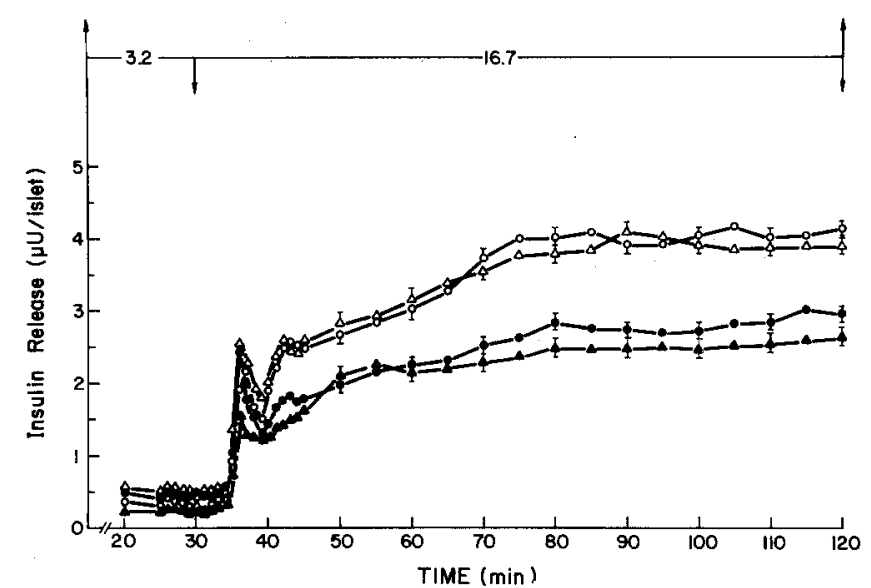

Fig.4. Effect of pretreatment with vehicle or naloxone $(0.5 \mathrm{mg} / \mathrm{kg})$ on the inhibitory effect of lithium on glucose-induced insulin release. Following isolation, islets were perifused for $30 \mathrm{~min}$ with $3.2 \mathrm{mmol} / 1$ glucose. They were then exposed to $16.7 \mathrm{mmol} / 1$ glucose in a normal ionic composition medium; vehicle-pretreated islets $(O)$ and naloxone-pretreated islets $(\Delta)$ or in a lithium $(5 \mathrm{mmol} / \mathrm{l})$ medium; vehiclepretreated islets $(\mathbf{O})$ and naloxone-pretreated islets $(\Delta)$. All conditions were always carried out in parallel chambers. Values in the curves are means \pm SEM of results from 6 to 8 separate experiments

The effect of pretreatment of rats with DHE on lithium inhibition of glucose-stimulated insulin release is shown in Figure 3. When islets isolated from DHE-pretreated rats were perifused with the lithium $(5 \mathrm{mmol} / \mathrm{l})$ medium $+16.7 \mathrm{mmol} / 1$ glucose, the inhibitory effect of lithium on the second phase of glucose-stimulated insulin release was abolished. Integrated insulin release during the second phase was $235 \pm 19 \mu \mathrm{U} /$ islet for the DHE - pretreated islets + lithium, and not significantly different from saline pretreated islets + control medium

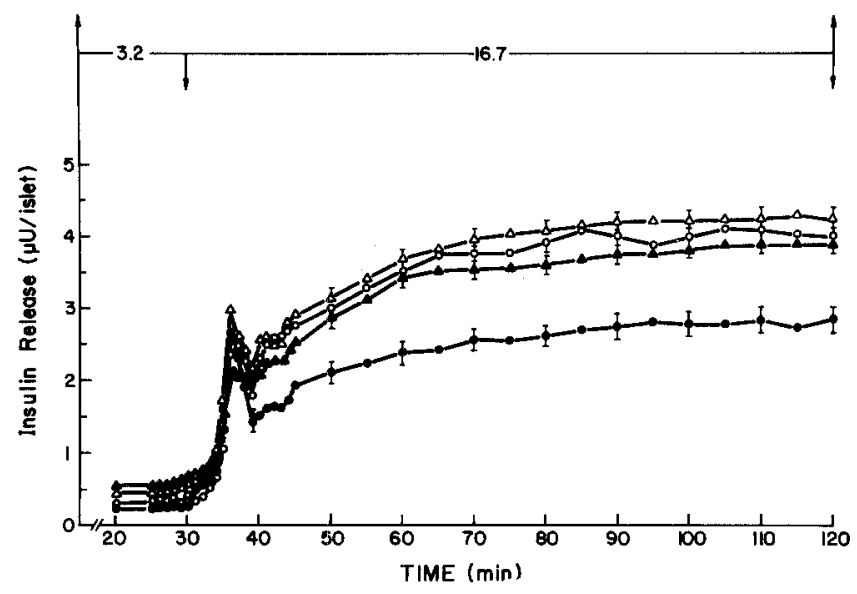

Fig.5. Effect of pretreatment with vehicle or dihydroergotamine and naloxone on the inhibitory effect of lithium on glucose-induced insulin release. Following isolation, islets were perifused for $30 \mathrm{~min}$ with $3.2 \mathrm{mmol} / 1$ glucose. They were then exposed to $16.7 \mathrm{mmol} / 1$ glucose in a normal ionic composition medium; vehicle pretreated islets $(O)$ and drug-pretreated islets $(\Delta)$ or in a lithium $(5 \mathrm{mmol} / \mathrm{l})$ medium; vehicle-pretreated islets $(\boldsymbol{O})$ and drug-pretreated islets $(\boldsymbol{\Delta})$. All conditions were always carried out in parallel chambers. Values in the curves are means \pm SEM of results from 6 to 8 separate experiments

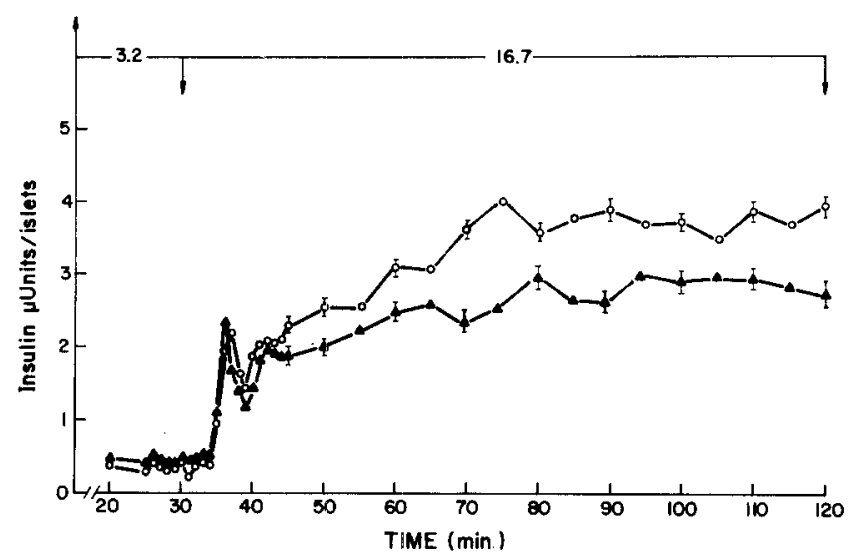

Fig. 6. Effect of long-term lithium treatment on glucose-induced in sulin release. Islets from control rats $(O)$ and from lithium treated rats (A) were perifused for $30 \mathrm{~min}$ with $3.2 \mathrm{mmol} / 1$ glucose. They were then exposed to $16.7 \mathrm{mmol} / 1$ glucose in a normal ionic composition medium. Both conditions were always carried out in parallel chambers. Values in the curves are means \pm SEM of results from 8 to 10 separate experiments

$(259 \pm 18)$. Integrated insulin release was significantly different from saline pretreated islets + lithium (150 \pm $11, p<0.05)$. DHE pretreatment had no effect on glucose-stimulated insulin when islets were perifused with the control medium $(257 \pm 15 \mu \mathrm{U} /$ islet $)$.

The effect of pretreatment of rats with naloxone on the inhibitory effect of lithium on the second phase of glucose-stimulated insulin release is shown in Figure 4. Pretreatment of rats with the opiate antagonist, naloxone, did not modify the inhibitory effect of lithium. In- 
tegrated insulin release during the second phase was $162 \pm 17 \mu \mathrm{U} /$ islet for naloxone pretreated islets + lithium, and not significantly different from saline pretreated islets + lithium (188 \pm 18$)$. It was significantly different from saline pretreated islets + control medium $(272 \pm 22, p<0.05)$. Naloxone pretreatment had no effect on glucose-stimulated insulin release when islets were perifused with control medium $(258 \pm 25 \mu \mathrm{U} /$ islet).

When pretreatment of DHE and naloxone were combined (Fig. 5), the second phase of the glucose-stimulated insulin release inhibition caused by lithium was prevented. Integrated insulin release during the second phase was $258 \pm 16 \mu \mathrm{U} /$ islet for pretreated islets + lithium, and not significantly different from saline pretreated islets + control medium $(263 \pm 24)$. It was significantly different from saline pretreated islets + lithium $(161 \pm 13, p<0.05)$. The combined pretreatment of these two drugs had no effect on glucose-stimulated insulin release when islets were perifused with control medium $(271 \pm 20 \mu \mathrm{U} /$ islet $)$.

\section{Effect of long-term lithium treatment on glucose-induced insulin release}

Administration of lithium in the drinking water did not significantly affect fluid consumption compared to the water intake of the control group, nor did any significant differences in body weight occur between the two groups (final body weight $310 \pm 25$ and $330 \pm 10 \mathrm{~g}$ for lithium and control groups, respectively).

A biphasic pattern of insulin release was demonstrated in islets from both lithium-treated and control rats following stimulation with $16.7 \mathrm{mmol} / 1$ glucose, although the amount of insulin released during the second phase was significantly lower in the lithium-treated rats than in the control rats $(192 \pm 11$ and $274 \pm$ $15 \mu \mathrm{U} /$ islet, respectively) $(p<0.05)$. No inhibition of the first phase was observed (Fig. 6).

\section{Discussion}

Several authors have found an inhibitory effect on glucose-induced insulin secretion when sodium was replaced or partially replaced by lithium in order to study the effect of low sodium concentrations on insulin release [7-9]. In addition, it has been shown that in the intact rat lithium exerts an inhibitory effect on glucose-induced insulin release [2,3]. The present study confirms previous findings [4] that in vitro lithium has an inhibitory effect on insulin secretion; glucose-induced insulin release was partially inhibited by lithium. Moreover, there was a clear difference in the sensitivity of the two phases of insulin release towards lithium; whereas the first phase in perifusion was not significantly affected by lithium, the second phase was reduced by $35 \%$. To determine whether these effects of lithium on both phases of glucose-induced insulin release were longlasting, we examined the effect of long-term lithium administration on the islets. The decrease in the secretory rate for insulin during the second phase of glucose-induced release in islets from lithium-treated rats showed that the inhibitory effect of lithium did not revert to normal under in vitro conditions in which lithium was absent from the perifusion medium. Thus, long-term administration of lithium resulted in a significant inhibition of the second phase of glucose-induced insulin release.

The present results also demonstrate that pretreatment of rats with DHE, an alpha-adrenergic receptor blocker, prevented lithium from inhibiting glucose-stimulated insulin release in islets. This suggests that alphaadrenergic drive may play a role in lithium-induced insulin release inhibition, as has been described in vivo [3]. Morphological studies have shown that islets of most mammals contain sympathetic and parasympathetic nerve terminals that end blindly near the islet cells $[10,11]$. Although effects of lithium on the action of the major neurotransmitters have been reported, the neurochemical basis of lithium action is still not understood. Studies on the effect of lithium on adrenergic-receptor properties have provided conflicting data. Some authors $[12,13]$ have observed that alpha-adrenergic receptor binding increased following chronic lithium treatment. Treiser et al. [14], on the other hand, were not able to observe any increases in alpha-adrenergic receptors after administration of lithium. Correlations have been described between alpha-adrenergic inhibitions of insulin release and of calcium uptake by the islet cells $[15,16]$. That lithium-inhibited glucose-induced insulin release can be relieved by DHE supports the idea of an alpha-adrenoceptor mediated response. As DHE is a non-selective alpha receptor blocker, further studies are needed to decided whether the inhibitory influence of lithium is an alpha-1 or an alpha- 2 response, as several studies have established that glucose-stimulated insulin release is sensitive to alpha-2 agonists $[17,18]$.

Previous findings obtained in vivo suggest that opioids may be involved in the inhibitory effect of lithium on glucose-stimulated insulin release [3]. In addition, chronic lithium administration has been found to increase levels of enkephalin in the striatum [19]. Nevertheless, we found that naloxone pretreatment failed to counteract the effect of lithium on glucose-stimulated insulin secretion in vitro. Our results indicate, therefore, that the mechanism of action of lithium in vivo may differ from its action in vitro. Whereas the action of lithium seems to be regulated through the opioid-catecholamine system in vivo, opioids seem not to be implicated in lithium inhibition of glucose-induced insulin release in vitro. Further studies to test this notion are in progress.

Acknowledgments. The authors thank Ms. Isabel Solana for technical assistance. This study was supported by Grant $608 / 429$ from: Comisión Asesora de Investigación Cientifica y Técnica. 


\section{References}

1. Shopsin B, Stern S, Gerson S (1972) Altered carbohydrate metabolism during treatment with lithium carbonate. Arch Gen Psychiatry 26: 566-571

2. Shah JH, Pishdad G (1980) The effect of lithium on glucose- and tolbutamide-induced insulin release and glucose tolerance in the intact rat. Endocrinology 107: 1300-1304

3. Fontela T, Garcia Hermida O, Gómez-Acebo J (1986) Blocking effect of naloxone, dihydroergotamine and adrenalectomy in lithium-induced hyperglycaemia and glucose intolerance in the rat. Acta Endocrinol 111: 342-348

4. Anderson JH, Blackard WG (1978) Effect of lithium on pancreatic islet insulin release. Endocrinology 102: 291-295

5. Lacy PE, Kostianovsky M (1967) Method for the isolation of intact islets of Langerhans from the rat pancreas. Diabetes 16:35-39

6. Lacy PE, Walker MM, Fink CJ (1972) Perifusion of isolated rats islets, ,in vitro“. Participation of the microtubular system in the biphasic release of insulin. Diabetes 21: 987-998

7. Hales CN, Milner RDG (1968) The role of sodium and potassium in insulin secretion from rabbit pancreas. J Physiol (Lond) 194: 725-743

8. Malaisse WJ, Malaisse-Lagae F, Brisson G (1971) The stimulussecretion coupling of glucose-induced insulin release. II Interaction of alkali and alkaline earth cations. Horm Metab Res 3: $65-70$

9. Lambert AE, Hequin JC, Malvaux P (1974) Cationic enviroment and dynamics of insulin secretion. I Effect of low concentration of sodium. Endocrinology 95: 1069-1077

10. Smith PH, Porte D jr (1976) Neuropharmacology of the pancreatic islets. Annu Rev Pharmacol Toxicol 16: 269-285

11. Woods SC, Porte D jr (1974) Neural control of the endocrine pancreas. Physiol Rev 54: 596-619
12. Rosenblatt JE, Pert CB, Tallman JF, Pert A, Bunney WE jr (1979) The effect of imipramine and lithium on alpha- and beta-receptor binding in rat brain. Brain Res 160: 186-191

13. Kafka MS, Wirz-Justice A, Naber D, Marangos PJ, O'Donahue TL, Wehr TA (1982) Effect of lithium on circadian neurotransmitter receptor rhythms. Neuropsychobiology 8:41-50

14. Treiser SL, Kellar KJ (1979) Lithium effects on adrenergic receptor supersensitivity in rat brain. Eur J Pharmacol 58: 85-86

15. Malaisse-Lagae F, Malaisse WJ (1971) The stimulus-secretion coupling of glucose-induced insulin release. III Uptake of Calcium by isolated islets of Langerhans. Endocrinology 88:72-80

16. Wollheim CB, Kikuchi M, Renold AE, Sharp GWG (1977) Somatostatin and epinephrine induced modifications of Ca fluxes and insulin release in rat pancreatic islets maintained in tissue culture. J Clin Invest 60: 1165-1173

17. Leclercq-Meyer V, Herchuelz A, Valverde I, Couturier E, Marchand J, Malaisse WJ (1980) Mode of action of clonidine upon islet function. Dissociated effects upon the time course and magnitude of insulin release. Diabetes 29: 193-200

18. Nakaki T, Nakadate T, Ishii K, Kato R (1981) Postsynaptic Alpha-2 adrenergic receptors in isolated rat islets of Lagnerhans: Inhibition of insulin release and cyclic 3'-5'-Adenosin monophosphate accumulation. J Pharmacol Exp Ther 216: 607-612

19. Gillin JC, Hong JS, Yang H-YT, Costa E (1978) (Met-s)-Enkephalin content in brain regions of rats treated with lithium. Proc Natl Acad Sci USA 75: 2991-2994

Received: 6 August 1986

and in revised form: 26 January 1987

Dr. T.Fontela

Inst. G. Marañón, C.I. B.

Velázquez 144

28006 Madrid

Spain 